\title{
XRD, AFM, IR and TGA Study of Nanostructured Hydroxyapatite
}

Mirta Mir ${ }^{\mathrm{a}}$, Fabio Lima Leite ${ }^{\mathrm{b} *}$, Paulo Sérgio de Paula Herrmann Junior ${ }^{\mathrm{c}}$, Fabio Luiz Pissetti, Alexandre Malta Rossi ${ }^{\mathrm{d}}$, Elizabeth Lima Moreira ${ }^{\mathrm{d}}$, Yvonne Primerano Mascarenhas ${ }^{\mathrm{e}}$

\author{
anstitute of Exact Science, Federal University of Alfenas - UNIFAL, \\ CEP 37130-000, Alfenas, MG, Brazil \\ ${ }^{\mathrm{b}}$ Department of Physics, Chemistry and Mathematics, Federal University of São Carlos - UFSCar, \\ CEP 18052-780, Sorocaba, SP, Brazil \\ 'Alan G. MacDiarmid Institute for Innovation and Business, National Nanotechnology Laboratory for \\ Agribusiness - LNNA, Embrapa Agricultural Instrumentation, São Carlos, SP, Brazil \\ ${ }^{\mathrm{d} B r a z i l i a n}$ Center for Physics Research - CBPF, Urca, RJ, Brazil \\ ${ }^{\mathrm{e}}$ Department of Physics and Informatics, Physics Institute of São Carlos, University of São Paulo - USP, \\ São Carlos, SP, Brazil
}

Received: March 29, 2012; Revised: May 05, 2012

\begin{abstract}
In this work, the synthetic hydroxyapatite (HAP) was studied using different preparation routes to decrease the crystal size and to study the temperature effect on the HAP nano-sized hydroxyapatite crystallization. X-ray diffraction (XRD) analysis indicated that all samples were composed by crystalline and amorphous phases. The sample with greater quantity of amorphous phase (40\% of total mass) was studied. The nano-sized hydroxyapatite powder was heated and studied at $300,500,700,900$ and $1150^{\circ} \mathrm{C}$. All samples were characterized by XRD and their XRD patterns refined using the Rietveld method. The crystallites presented an anisotropic form, being larger in the [001] direction. It was observed that the crystallite size increased continuously with the heating temperature and the eccentricity of the ellipsoidal shape changed from 2.75 at $300{ }^{\circ} \mathrm{C}$ to $1.94,1.43,1.04$ and 1.00 respectively at $500,700,900$ and $1150^{\circ} \mathrm{C}$. In order to better characterize the morphology of the HAP the samples were also examined using atomic force microscopy (AFM), infrared spectrometry (IR) and thermogravimetric analysis (TGA).
\end{abstract}

Keywords: nanocrystals, AFM, XRD, hydroxyapatite, Rietveld, TGA e IR

\section{Introduction}

The hydroxyapatite (HAP), $\mathrm{Ca}_{10}\left(\mathrm{PO}_{4}\right)_{6}(\mathrm{OH})_{2}$, is one of most important bioceramics for hard tissue reconstruction. This application is due to the similarity of the composition of this material with that of the mineral part of bone and tooth $^{1,2}$. The natural bone model presents a combination of organic and inorganic phases with nanometer size (an average length of $50 \mathrm{~nm}$ and $25 \mathrm{~nm}$ in width) $)^{3}$. The small size of the apatite crystalite is a very important factor related with the biological and structural properties such as surface activity, dissolution rate, molding and sintering behavior ${ }^{4-7}$. In order to obtain nanoapatites out of the biological environment and similar to the one in bone, is very important to study how their properties change with the dimensions. In the last years great efforts have been made to produce HAP with low crystal dimensions ${ }^{4-6}$. In some of these studies composites containing HAP and organic molecules have been precipitated in experimental conditions in which the HAP crystals achieved dimensions close to those of bone apatite $^{8}$. Despite many years of experimental synthesis, characterization, and increasing use in applications, many doubts still remain concerning the structure and formation of these nano-crystals. In this work, the synthetic hydroxyapatite

*e-mail: fabioleite@ufscar.br
(HAP) was prepared using several drying routes to decrease the crystal size and the temperature effect on the HAP nano-sized hydroxyapatite crystallization was studied. X-ray diffraction (XRD) and atomic force microscopy (AFM) were used in order to characterize the nano-sized powder and the powder after thermal treatments. The combination of results obtained from Rietveld refinements of XRD patterns, AFM analysis, infrared spectrometry (IR) and thermogravimetric analysis (TGA) permit a detailed description of changes on particle morphology and particle size with the increase of temperature.

\section{Experimental}

\subsection{Materials preparation}

The hydroxyapatite powder were prepared by dropwise addition of calcium nitrate to the ammonium phosphate solution under controlled conditions of temperature, $\mathrm{pH}$, stirring velocity, reagent concentration, addition rate and aging time. The precipitate was separated by filtration, repeatedly washed with deionized water and dried at $37{ }^{\circ} \mathrm{C}$ (sample 37c) or lyophilized for 8 or 69 hours (samples 
ly8h and ly69h respectively). The synthesis procedure was adjusted in order to produce materials with very small particle size. To study the effect of temperature on crystallization the 69 hours lyophilized sample was heated at $300,500,700,900$ and $1150{ }^{\circ} \mathrm{C}$ (samples 300c, 500c, $700 \mathrm{c}, 900 \mathrm{c}$ and $1150 \mathrm{c}$, respectively)

\subsection{X-ray diffraction and rietveld refinement}

The X-ray powder diffraction patterns were collected with a Rigaku Rota-flex, using a flat-plate Bragg-Brentano geometry, and graphite monochromated $\mathrm{CuK} \alpha$ radiation. The powder diffraction patterns were recorded in the range of $20-90^{\circ}$, with a step of $0.02^{\circ}$ at 5 second/step. Structural refinement was performed using the Rietveld method as implemented in the computer program package FullProf-Suite 9 . The HAP parameters given by Kay et al. ${ }^{10}$ were employed as an initial model for crystal structure refinement. The lanthanum hexaboride (LaB6) standard material was used to model the instrumental resolution. The extraction of the crystallite size and microstrain components of the intrinsic diffraction profile was carried out with the Rietveld method of whole-pattern-fitting structurerefinement. The microstructural effects are treated using the TCH pseudo-Voigt profile function ${ }^{11}$. The intrinsic profile of a particular reflection due to size effect has an integral breadth $\beta_{\mathrm{s}}$, from the Scherrer formula $<\mathrm{D}>=\lambda /\left(\beta_{\mathrm{s}} \cos \theta\right)$ provides the volume averaged apparent size of the crystallites in the direction normal to the scattering planes. If the instrumental resolution function is provided after refinement, the program Fullprof calculates the apparent size (in angstrom) along each reciprocal lattice vectors. To obtained the anisotropic size, the spherical harmonics model was using. The intrinsic profile of a particular reflection due to a strain effect has an integral breadth $\beta_{\mathrm{d}}$, the apparent strain is defined as $\eta=\beta_{d} \cot (\theta)^{12}$. To conclude if the model is consistent with our data, or to select the best refinement, for each model the $\mathrm{R}_{\mathrm{wp}}$ (weighted profile agreement factor ) was calculated to obtain the probability of correcteness of each model, as suggested by Hamilton ${ }^{13}$. In all cases, except for $1150 \mathrm{c}$, the atomic positions were refined. In the samples $l y 8 h, l y 69 h$, and $37 \mathrm{c}$ the best model was obtained refining the water occupation in the structure. The Table 1 shows the agreement factor between observed and calculated profiles obtained from Rielveld refinement for each sample.

\section{Atomic force microscopy (AFM)}

In order to compare with the XRD results, particle size and morphology were analyzed using atomic force microscopy (AFM). All measurements were carried out on a Topometrix TMX 2010 Discoverer AFM, operating in contact mode. The cantilevers have a spring constant $\mathrm{k}=0.03 \mathrm{Nm}^{-1}$ and tip curvature radius $\mathrm{R}=235 \mathrm{~nm}$ (MicroleversTM -Veeco Metrology Group). The values of length, width and thickness of the cantilever and the tip radius were measured with a Philips model XL30-FEG SEM. The cantilever elastic constant was calculated using the equation used by Leite et al. ${ }^{14}$. The AFM images were analyzed using WSXM (Nanotec Electronica S.L.) software ${ }^{15}$. The samples were prepared using the layer-by-layer technique ${ }^{16,17}$, where HAP particles are deposited onto mica muscovite substrates. The solution of HAP was prepared in deionized water at a concentration of $1 \mathrm{gL}^{-1}$ under continuous stirring for 6 hours. The films were produced by immersion of the substrate into solution for 3 minutes for each layer and after to deposition the plates were dried in a desiccator for 24 hours. The presence of aggregates on the surface was a common characteristic irrespective of the type of substrate and deposition. The size of the particles were determined from the AFM images, after correcting for the effect due to the similar sizes of the tip and particles using the geometric relation described in the literature ${ }^{18,19}$.

\subsection{Fourier transform Infrared spectrometry (FTIR) and Thermogravimetric analysis (TGA)}

FTIR spectra of the materials were obtained as pressed $\mathrm{KBr}$ pellets, with $4 \mathrm{~cm}^{-1}$ of resolution, on a Shimadzu IR Prestige 21 spectrophotometer. Thermogravimetric analyses were carried out on an Instruments Thermoanalyzer, model SDTQ600. The measurements were performed under a flowing nitrogen atmosphere, with a heating rate of $10{ }^{\circ} \mathrm{C} / \mathrm{min}$ in the range from 30 to $1200{ }^{\circ} \mathrm{C}$.

\section{Results and Discussion}

The Rietveld refinements of XRD patterns showed that lyophilized samples are formed with greater amounts of amorphous phase $(-20 \%$ and $40 \%$ for 8 and 69 hours of lyophilization, respectively) as compared with ones dried at $37{ }^{\circ} \mathrm{C}(10 \%$ in the sample $37 \mathrm{c})$ (see Figure 1). From Figure 1 and 2 one infers that crystalline phase of sample lyophilized for 8 hours had smaller average apparent crystallite sizes (68 $\AA$ ), larger strain (39.49[0.044]) the number in brakets is measure the degree of anisotropy) and larger unit cell volume $\left(529.37(4) \AA^{3}\right)$ than sample lyophilized for 69 hours or dried at $37^{\circ} \mathrm{C}$ (see Figure 2). It seems that crystallization water was removed from the HAP structure upon drying, thus decreasing the unit cell volume and the strain while the crystallite mean size increased (see Figures 1 and 2). Since the sample lyophilized for 69 hours exhibited larger amounts of amorphous phase, it was selected to study the effect from the temperature on the crystallization. The drying procedure also affected the structural water present in the sample; in sample lyophilized for 8 hours (ly8h) the water occupies $81 \%$ of the site (Wyckoff site: $4 e$ ), the lyophilized for 69 hours $(l y 69 h), 71 \%$ and in the dried at $37{ }^{\circ} \mathrm{C}(37 \mathrm{c}), 100 \%$.

Table 1. The agreement factor $\left(\mathrm{R}_{\mathrm{Bragg}}\right.$ and $\left.\mathrm{R}_{\mathrm{wp}}\right)$ between observed and calculated profiles obtained from Rietveld refinement.

\begin{tabular}{lcccccccc}
\hline \multicolumn{1}{c}{ Sample } & $\boldsymbol{l y} \boldsymbol{8 \boldsymbol { h }}$ & $\mathbf{l y 6 9 h}$ & $\mathbf{3 7} \boldsymbol{c}$ & $\mathbf{3 0 0} \boldsymbol{c}$ & $\mathbf{5 0 0} \boldsymbol{c}$ & $\mathbf{7 0 0} \boldsymbol{c}$ & $\mathbf{9 0 0} \boldsymbol{c}$ & $\mathbf{1 1 5 0} \boldsymbol{c}$ \\
\hline $\mathrm{R}_{\text {Bragg }}(\%)$ & 1.59 & 3.39 & 2.07 & 2.90 & 2.27 & 3.53 & 3.30 & 3.82 \\
$\mathrm{R}_{w p}(\%)$ & 4.19 & 4.59 & 4.36 & 5.74 & 4.89 & 5.58 & 5.74 & 11.2 \\
\hline
\end{tabular}


Figure 3 shows that crystallites presented an anisotropic form, being longer in the [001] direction. With the rise of annealing temperature, the crystallites size increased and the strain decreased to zero at $1150^{\circ} \mathrm{C}$ as shown in Figure 1 . The

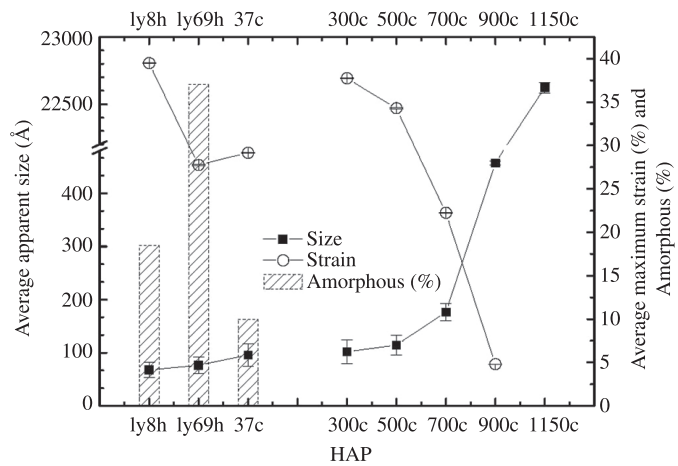

Figure 1. Visualization of the average apparent size (A), average maximum strain (\%), and $\%$ of amorphous phase obtained from Rietveld refinement for a) ly8h, b) ly69h, c 37c, d) 300c, e) 500c, f) $700 \mathrm{c}$, g) $900 \mathrm{c}$ and h) $1150 \mathrm{c}$. The left hand axes correspond to average apparent size (isotropy) and the right hand axis correspond to average maximum strain whith the corresponding standard deviation (anisotropy) and the \% of amorphous phase obtained for each sample. sample lyophilized for 69 hours (ly69h), which had large amount of amorphous phase, exhibited greater deformation in the tetrahedron where the distance among the atoms $\mathrm{P}-\mathrm{O} 2$ is greater that $\mathrm{P}-\mathrm{O} 1$ and $\mathrm{P}-\mathrm{O} 3$ and the distance among $\mathrm{P}-\mathrm{Ca} 1$ is also greatest (see Table 2). The sample ly69h presents the greatest amount of amorphous phase and deformation of the phosphate tetrahedra in the crystalline phase. Nevertheless, its crystalline phase remained more isotropic compared with the samples and $37 \mathrm{c}$ and ly8h. At

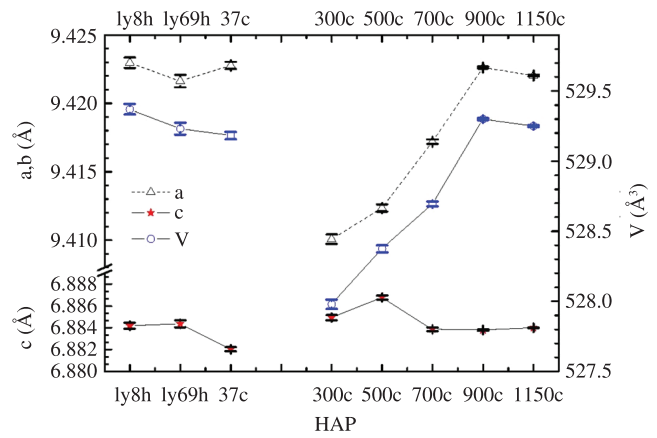

Figure 2. The lattice dimensions and volume of HAP samples determined by the Rietveld refinement with the corresponding error.

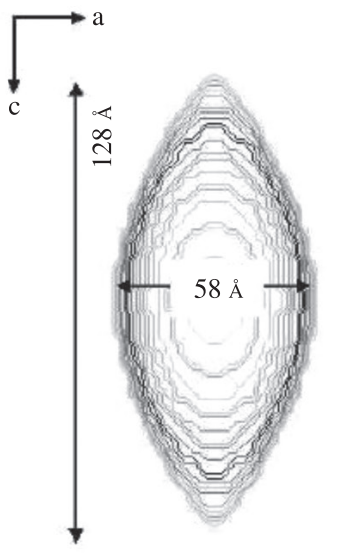

(a)

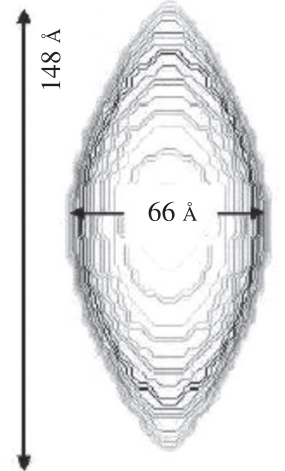

(b)

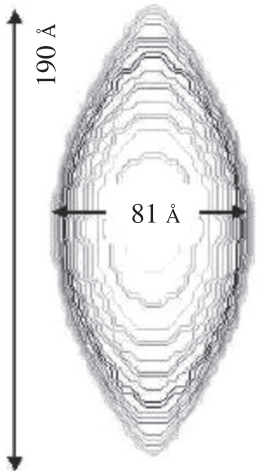

(c)



(d)

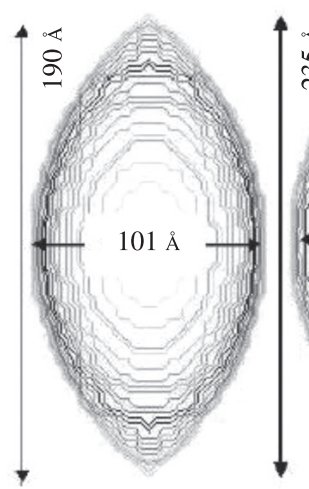

(e)



(f)

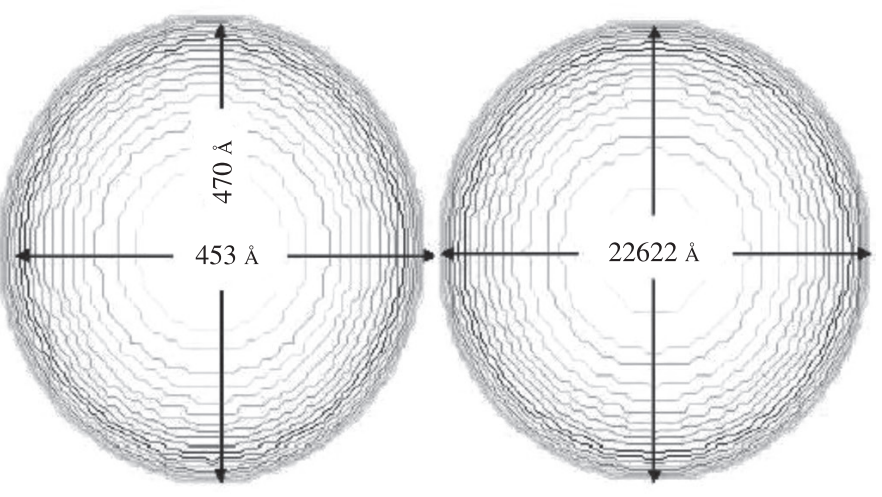

(g) (h)

Figure 3. Visualization of the average crystallite shape and size obtained from Rietveld refinement for a) $l y 8 h$, b) $l y 69 h$, c) $37 \mathrm{c}$, d) $300 \mathrm{c}$, e) $500 \mathrm{c}, \mathrm{f}) 700 \mathrm{c}, \mathrm{g}$ ) $900 \mathrm{c}$ and h) $1150 \mathrm{c}$. The cristalites are greater in the direction of the axis c, presenting an isotropic behavior in a and b axis. 
$300{ }^{\circ} \mathrm{C}$ (sample 300c) where great part of the water in the sample leaves and the volume decreases considerably, the phosphate tetrahedron deformations are smaller and the distances between $\mathrm{P}$ - Ca1 are also smaller.

The AFM images of the surface topography of HAP particles deposited on a mica substrate in figure 4 point to an increased particle size for increasing temperatures $(300,500$, 700,900 and $1150{ }^{\circ} \mathrm{C}$ ). Aggregates on the surface appeared for all samples. The size of the particles was determined from the AFM images. The nanoparticles were anisotropic with ellipsoidal geometry (Figure 3 and 4 ) with size varying between 220 and $23000 \AA$ for the sample lyophilized for 69 hours and the one sintered at $1150{ }^{\circ} \mathrm{C}$, respectively, in agreement with the values obtained by XRD (see Table 3 ).

The FTIR spectrum of HAP samples 37c, 300c and 500c presents a broader phosphate band in the $1000 \mathrm{~cm}^{-1}$ region

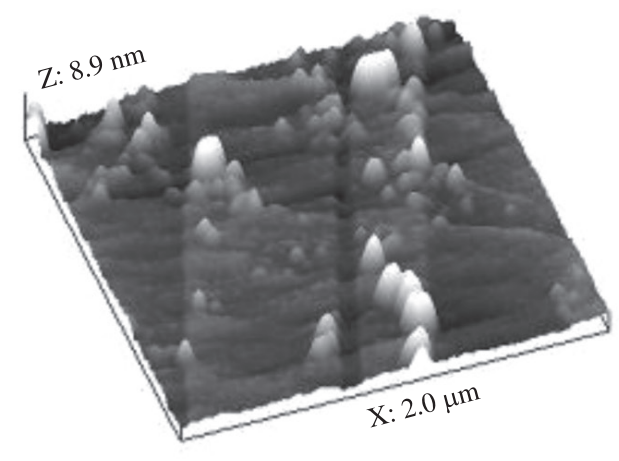

(a)

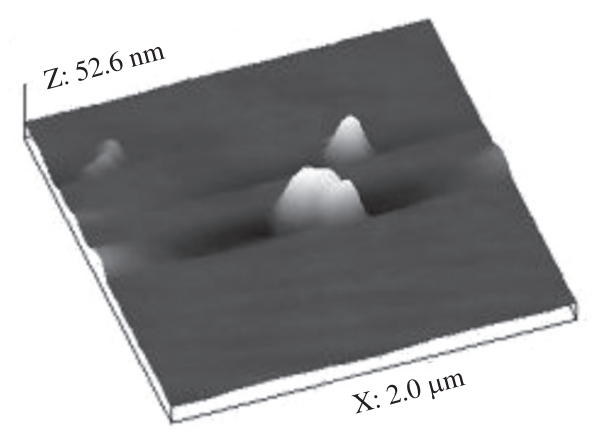

(c)

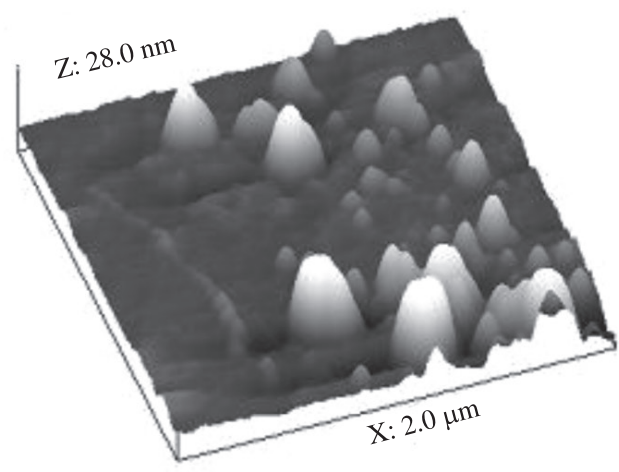

(e)

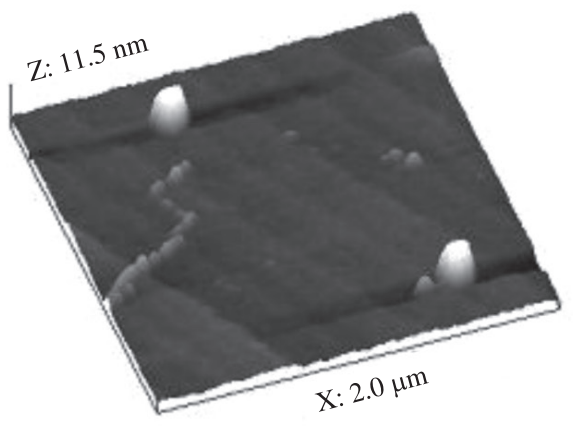

(b)

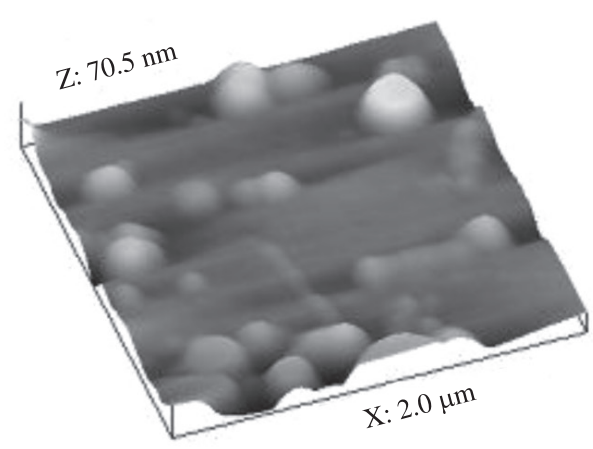

(d)

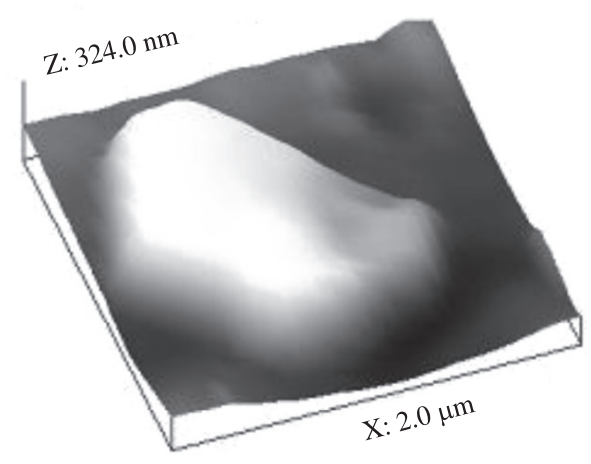

(f)

Figure 4. AFM topography of HAP particles deposited on mica by self-assembly by 3 minutes. a) 37c, b) 300c, c) 500c, d) 700c, e) $900 \mathrm{c}$ and f) $1150 \mathrm{c}$. 
and the absence of $\mathrm{OH}^{-}$bands at $3570 \mathrm{~cm}^{-1}$ and $631 \mathrm{~cm}^{-1}$ (see Figure 5). These results are typical of nanocrystalline HAP. For samples 700c, 900c and $1150 \mathrm{c}$ the band for $\mathrm{PO}_{4}{ }^{3-}$ vibrational modes become better defined and the $\mathrm{OH}^{-}$bands are observed, as consequence of the increase in particle size. The incorporation of impurities into the HAP structure probably perturbs the $\mathrm{OH}^{-}$and $\mathrm{PO}_{4}{ }^{3-}$ vibrational modes. As reported $^{20}$, the small crystal size on the nanocrystalline HAP presents a more effective incorporation of $\mathrm{CO}_{3}{ }^{2-}$ and $\mathrm{H}_{2} \mathrm{O}$ groups into $\mathrm{PO}_{4}^{-3}$ sites. The FTIR for HAP samples $700 \mathrm{c}$,

Table 2. Interatomic distances of the most nearby neighbors for the crystallographic site and standard deviations obtained from the refinement (in $\AA$ ).

\begin{tabular}{|c|c|c|c|c|c|c|c|c|}
\hline \multirow{2}{*}{$\begin{array}{c}\text { Distance } \\
\text { (neighbors) }\end{array}$} & \multicolumn{8}{|c|}{ Samples } \\
\hline & ly $8 \mathrm{~h}$ & ly69h & $37 c$ & $300 c$ & $500 c$ & $700 c$ & $900 c$ & $1150 c$ \\
\hline P-01 & $1.5316(63)$ & $1.5391(80)$ & $1.5437(53)$ & $1.5696(65)$ & $1.5592(51)$ & $1.5611(48)$ & $1.5602(38)$ & 1.5359 \\
\hline P-02 & $1.5605(69)$ & $1.6035(88)$ & $1.5579(55)$ & $1.5680(70)$ & $1.5625(54)$ & $1.5614(50)$ & $1.5429(41)$ & 1.5456 \\
\hline 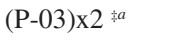 & $1.5182(31)$ & $1.5407(42)$ & $1.5358(27)$ & $1.5599(33)$ & $1.5358(26)$ & $1.5488(25)$ & $1.5571(21)$ & 1.5287 \\
\hline (P-Ca1) & $3.1889(32)$ & $3.2120(43)$ & $3.1994(28)$ & $3.1884(35)$ & $3.1985(27)$ & $3.1958(25)$ & $3.2110(19)$ & 3.2144 \\
\hline (P-Ca2) & $3.1521(34)$ & $3.1097(46)$ & $3.1176(29)$ & $3.1362(36)$ & $3.1183(28)$ & $3.0982(26)$ & $3.0851(20)$ & 3.0794 \\
\hline$(\mathrm{Ca} 1-01) \times 3^{\sharp b}$ & $2.4025(42)$ & $2.3884(55)$ & $2.3948(36)$ & $2.3827(44)$ & $2.3817(35)$ & $2.3972(33)$ & $3.3932(25)$ & 2.4067 \\
\hline$(\mathrm{Ca} 1-02) \times 3 \neq c$ & $2.4211(40)$ & $2.4054(64)$ & $2.4416(41)$ & $2.4148(51)$ & $2.4322(40)$ & $2.4326(37)$ & $2.4611(30)$ & 2.4534 \\
\hline$(\mathrm{Ca} 1-03) \times 3 \stackrel{\ddagger}{\stackrel{d}{2}}$ & $2.7531(37)$ & $2.7724(47)$ & $2.7849(31)$ & $2.7550(37)$ & $2.7665(29)$ & $2.7763(27)$ & $2.8071(23)$ & 2.8049 \\
\hline $\mathrm{Ca} 2-01$ & $2.7340(54)$ & $2.7342(70)$ & $2.7271(46)$ & $2.6862(57)$ & $2.7106(44)$ & $2.6895(42)$ & $2.6902(32)$ & 2.7051 \\
\hline $\mathrm{Ca} 2-02$ & $2.3797(67)$ & $2.3722(85)$ & $2.3599(54)$ & $2.3597(68)$ & $2.3580(52)$ & $2.3479(49)$ & $2.3435(40)$ & 2.3558 \\
\hline$(\mathrm{Ca} 2-03) \times 2 * e$ & $2.5941(40)$ & $2.5139(52)$ & $2.5484(34)$ & $2.5657(41)$ & $2.5531(32)$ & $2.5423(30)$ & $2.5197(25)$ & 2.5117 \\
\hline$(\mathrm{Ca} 2-03) \times 2$ & $2.3472(28)$ & $2.3583(37)$ & $2.3368(24)$ & $2.3206(29)$ & $2.3411(23)$ & $2.3245(23)$ & $2.3183(20)$ & 2.3463 \\
\hline$(\mathrm{Ca} 2-\mathrm{OH}) \times 2$ & $2.4063(35)$ & $2.3690(49)$ & $2.3967(25)$ & $2.4207(32)$ & $2.4030(25)$ & $2.3999(23)$ & $2.3975(19)$ & 2.3809 \\
\hline
\end{tabular}

${ }^{\dagger}$ Correspond to atomic positions calculated in the paper employed as an initial model ${ }^{5}$. In this sample (1150c) the atomic positions were not refined. ${ }^{\ddagger}$ Lengths repeated by symmetry. ${ }^{a} \mathrm{O}: x, y, \overline{\mathrm{z}}+1 / 2 ;{ }^{b} \mathrm{O}: \bar{y}, 1+(\bar{x}+y), z+1 / 2 ; 1+(\bar{x}+y), 1+(\bar{x}), z ;{ }^{c} \mathrm{O}: \bar{y}, x-y,-1+z ; x-y, 1+x, z-1 / 2 ; 1+(\bar{x}), 1+(\bar{y}), z-1 / 2$; ${ }^{d} \mathrm{O}: x-y, 1+x, \bar{z} ; \bar{y}, x-y, \bar{z}+1 / 2 ; 1+(\bar{x}), 1+(\bar{y}), \bar{z} ;{ }^{e} \mathrm{O}: x-y, 1+x, z+1 / 2 ; x-y, 1+x, \bar{z} ;{ }^{f} \mathrm{O}: x, 1+y, z ; x, 1+y, \bar{z}+1 / 2 ;{ }^{g} \mathrm{OH}: x, 1+y, z ; y, 1+(\bar{x}+y), \bar{z}$.

Table 3. The corrected length $\left(\mathrm{R}_{\mathrm{p}}\right.$ : radius of particle) calculated from the AFM topographic images for two different magnification and the average apparent crystallite sizes obtained by XRD.

\begin{tabular}{|c|c|c|c|}
\hline \multirow{2}{*}{ Temperature $\left({ }^{\circ} \mathbf{C}\right)$} & \multicolumn{2}{|c|}{ AFM } & \multirow{2}{*}{$\begin{array}{c}\text { XRD } \\
\text { Average apparent size }(\AA)\end{array}$} \\
\hline & $R p(\AA)$ (aggregates) $(10 \times 10 \mu \mathrm{m})$ & $R p(\AA)($ single $)(2 \times 2 \mu \mathrm{m})$ & \\
\hline 37 & $220<R p<4500$ & $220 \pm 70$ & $81 \times 190$ \\
\hline 300 & $200<R p<3400$ & $240 \pm 40$ & $87 \times 96$ \\
\hline 500 & $200<R p<300$ & $253 \pm 100$ & $101 \times 190$ \\
\hline 700 & $300<R p<500$ & $450 \pm 220$ & $164 \times 235$ \\
\hline 900 & $350<R p<6000$ & $600 \pm 210$ & $453 \times 470$ \\
\hline 1150 & $8000<R p<23000$ & $1500 \pm 5000$ & $22622 \times 22622$ \\
\hline
\end{tabular}

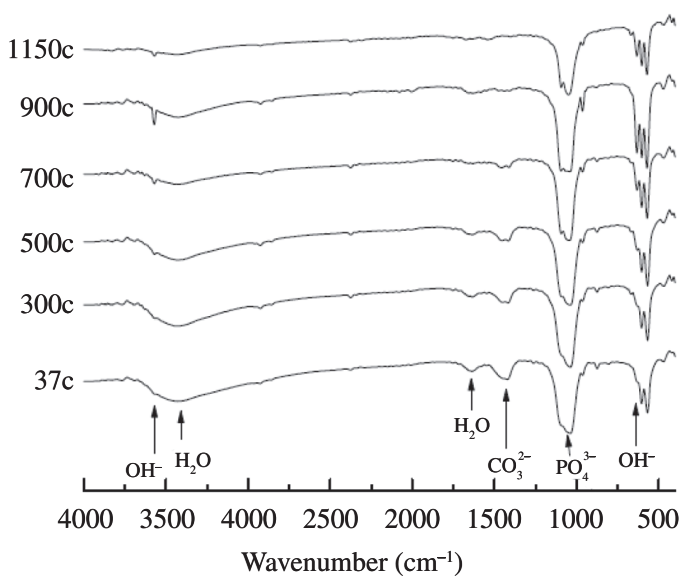

Figure 5. FTIR spectrum of HAP samples. 37c sample corresponds with nano-crystal size.

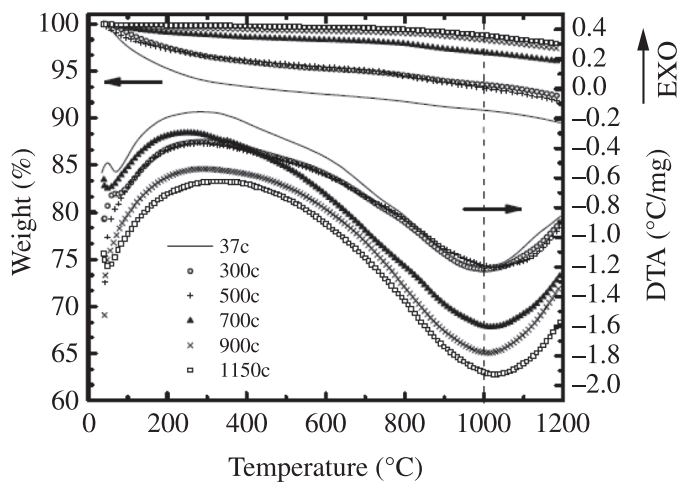

Figure 6. The data of differential thermal analysis (DTA) obtained for the HAP samples. $37 \mathrm{c}$ : corresponding to the nano size HAP without heat treatment. 
$900 \mathrm{c}$ and $1150 \mathrm{c}$ show a decrease in the bands of these species indicating a higher particle size. The results obtained are consistent with the X-ray and atomic force microscopy data. The data of differential thermal analysis (DTA) for the HAP samples obtained in several temperatures are shown in Figure 6. Here we can see that the HAP decomposition is affected due to the sample presenting smaller crystal sizes. The samples 300c and 500c show a similar behavior to the $37 \mathrm{c}$ sample. On the other hand, in the other samples with larger crystal sizes the peak appears after $1000{ }^{\circ} \mathrm{C}$.

\section{Conclusion}

It was shown that the drying procedure influences the quantity of amorphous phase and crystal size. The samples lyophilized for 69 hours presented the larger amount of amorphous phase. Analysis of the surface topography shows that the size of particles increased with the temperature in agreement with XRD results from the apparent average crystallite sizes. The AFM showed that the particles present an anisotropic form similar to obtained by XRD, where the crystallites are longer in the [001] direction and the eccentricity of the ellipsoidal shape changes from 2.75 at $300{ }^{\circ} \mathrm{C}$ to $1.94,1.43,1.04$ and 1.00 respectively at 500 , 700,900 and $1150^{\circ} \mathrm{C}$. The largest particle size was of the order of $23000 \AA$, estimated from the sample sintered at $1150{ }^{\circ} \mathrm{C}$.

\section{Acknowledgements}

The authors gratefully acknowledge the financial support provided by CNPq, FAPEMIG, FAPESP and to Embrapa for the facilities support.

\section{References}

1. Kim SY. Surface-engineered hydroxyapatite nanocrystal/ poly ( $\varepsilon$-caprolactone) hybrid scaffolds for bone tissue engineering. Journal of Applied Polymer Science. 2011; 121:1921-1929. http://dx.doi.org/10.1002/app.33749

2. Zhou H and Lee J. Nanoscale hydroxyapatite particles for bone tissue engineering. Acta Biomaterialia. 2011; 7:2769-2781. PMid:21440094. http://dx.doi.org/10.1016/j. actbio.2011.03.019

3. Vallet-Reg M. Evolution of bioceramics within the field of biomaterials. Comptes Rendus Chimie. 2010; 13:174-185.

4. Rey C, Combes C, Drouet C, Sfihi H and Barroug A. Physico-chemical properties of nanocrystalline apatites: implications for biominerals and biomaterials. Materials Science and Engineering: C. 2007; C27:198-205. http://dx.doi. org/10.1016/j.msec.2006.05.015

5. Kim S, Ryu HS, Shin H, Jung HS and Hong KS. Insitu observation of hydroxyapatite nanocrystal formation from amorphous calcium phosphate in calcium-rich solutions. Materials Chemistry and Physics. 2005; 91:500-506. http:// dx.doi.org/10.1016/j.matchemphys.2004.12.016

6. Wang F, Li MS, Lu YP, Qi YX and Liu YX. Synthesis and microstructure of hydroxyapatite nanofibers synthesized at $37{ }^{\circ} \mathrm{C}$. Materials Chemistry and Physics. 2006; 95:145-149. http://dx.doi.org/10.1016/j. matchemphys.2005.05.034

7. Shen SC, Chia L, Ng WK, Dong YC and Tan RBH. Solid-phase steam-assisted synthesis of hydroxyapatite nanorods and nanoparticles. Journal of Materials Science. 2010; 45:6059-6067. http://dx.doi.org/10.1007/ s10853-010-4691-1

8. Roveri N, Falini G, Sidoti M.C, Tampieri A, Landi E, Sandri $\mathrm{M}$ et al. Biologically inspired growth of hydroxyapatite nanocrystals inside self-assembled collagen fibers. Materials Science and Engineering: C. 2003; 23:441-446. http://dx.doi. org/10.1016/S0928-4931(02)00318-1

9. Rodríguez-Caravajal J. Guide to Program FULPROF for Rietveld Analysis of X-Ray and NeutronPowder Diffraction Patterns with a 'PC' and various other computers. Laboratoire Leon Brillouin; 2001.

10. Kay MI, Young RA and Posner AS. Crystal structure of hydroxyapatite. Nature. 1964; 204:1050-1052. PMid:14243377. http://dx.doi.org/10.1038/2041050a0

11. Thompson P, Cox D and Hastings J. Rielveld refinement of Debye-Scherrer synchrotron x-ray data from $\mathrm{Al}_{2} \mathrm{O}_{3}$. JAC - International Union of Crystallography. 1987; 20:79(83).

12. Stokes AR and Wilson AJC. The diffraction of X-rays by distorted crystal aggregates - I. Proceedings of the Physical Society. 1944; 56:174. http://dx.doi.org/10.1088/0959$5309 / 56 / 3 / 303$

13. Hamilton WC. Neutron diffraction investigation of the $119 \mathrm{~K}$ transition in magnetite. Physical Review. 1958; 110:1050-1057. http://dx.doi.org/10.1103/PhysRev.110.1050

14. Leite FL, Riul JA and Herrmann PSP. Mapping of adhesion forces on soil minerals in air and water by Atomic Force Spectroscopy (AFS). Journal of Adhesion Science and Technology. 2003; 17:2141-2156. http://dx.doi. org/10.1163/156856103772150751

15. Horcas I, Fernandez R, Gomez-Rodríguez JM, Colchero J, Herrero JG and Baro AM. WSXM: A software for scanning probe microscopy and a tool for nano technology. Review of Scientific Instruments. 2007; 78:013705-1-013705-8. PMid:17503926. http://dx.doi.org/10.1063/1.2432410

16. Decher G, Hong J and Schmitt J. Buildup of ultrathin multilayer films by a self-assembly process .3 . Consecutively alternating adsorption of anionic and cationic polyelectrolytes on charged surfaces. Thin Solid Films. 1992; 210-211:831-835. http:// dx.doi.org/10.1016/0040-6090(92)90417-A

17. Leite FL, Paterno LG, Borato CE, Herrmann PSP,Oliveira Junior ON and Mattoso LHC. Study on the adsorption of poly (o-ethoxyaniline) nanostructured films using atomic force microscopy. Polymer. 2005; 46:12503-12510. http://dx.doi. org/10.1016/j.polymer.2005.07.108

18. Bushell G, Watson G, Holt S and Myhra S. Imaging and nano-dissection of TMV by atomic force microscopy. Journal of Microscopy. 1995; 180:174-181. http://dx.doi. org/10.1111/j.1365-2818.1995.tb03673.x

19. Leite FL, De Oliveira Neto M, Paterno LG, Ballestero MR, Polikarpov I, Mascarenhas YP et al. Nanoscale conformational ordering in polyanilines investigated by saxs and afm. Journal of Colloid and Interface Science. 2007; 316:376-387. PMid:17905261. http://dx.doi.org/10.1016/j.jcis.2007.08.069

20. Rossi AM, Da Silva MHP, Ramirez DBAJ, Mir M, Mascarenhas YP, Eon JG et al. Structural properties of hydroxyapatite with particle size less than 10 nanometers. Key Engineering Materials. 2007; 330-332:255-258. http://dx.doi.org/10.4028/ www.scientific.net/KEM.330-332.255 